\title{
The influence of midazolam on heart rate arises from cardiac autonomic tones alterations in Burmese pythons, Python molurus
}

\author{
Ivã Guidini Lopes ${ }^{\mathrm{a}, 1}$, Vinicius Araújo Armelin ${ }^{\mathrm{b}, \mathrm{d}, 1}$, Victor Hugo da Silva Braga ${ }^{\mathrm{c}, \mathrm{d}, 1}$, \\ Luiz Henrique Florindo ${ }^{\mathrm{a}, \mathrm{c}, \mathrm{d} \text {, }}$ \\ a Aquaculture Center (CAUNESP), São Paulo State University (UNESP), Via Prof. Paulo Donato Castellane, n/n, Jaboticabal, SP 14884-900, Brazil \\ b Department of Physiological Sciences, Federal University of São Carlos (UFSCar), Via Washington Luiz, km 235, São Carlos, SP 13565-905, Brazil \\ c Department of Zoology and Botany, São Paulo State University (UNESP), Cristóvão Colombo Street, 2265, São José do Rio Preto, SP 15054-000, Brazil \\ d National Institute of Science and Technology in Comparative Physiology (INCT - FAPESP/CNPq), Via 24A, 1515, Rio Claro, SP 13506-900, Brazil
}

\section{A R T I C L E I N F O}

\section{Keywords:}

Autonomic nervous system

Benzodiazepine

Heart rate

Midazolam

Python molurus

\begin{abstract}
A B S T R A C T
The $\mathrm{GABA}_{\mathrm{A}}$ receptor agonist midazolam is a compound widely used as a tranquilizer and sedative in mammals and reptiles. It is already known that this benzodiazepine produces small to intermediate heart rate (HR) alterations in mammals, however, its influence on reptiles' HR remains unexplored. Thus, the present study sought to verify the effects of midazolam on HR and cardiac modulation in the snake Python molurus. To do so, the snakes' HR, cardiac autonomic tones, and HR variability were evaluated during four different experimental stages. The first stage consisted on the data acquisition of animals under untreated conditions, in which were then administered atropine $\left(2.5 \mathrm{mg} \mathrm{kg}^{-1}\right.$; intraperitoneal), followed later by propranolol $\left(3.5 \mathrm{mg} \mathrm{kg}{ }^{-1}\right.$; intraperitoneal) (cardiac double autonomic blockade). The second stage focused on the data acquisition of animals under midazolam effect ( $1.0 \mathrm{mg} \mathrm{kg}^{-1}$; intramuscular), which passed through the same autonomic blockade protocol of the first stage. The third and fourth stages consisted of the same protocol of stages one and two, respectively, with the exception that atropine and propranolol injections were reversed. By comparing the HR of animals that received midazolam (second and fourth stages) with those that did not (first and third stages), it could be observed that this benzodiazepine reduced the snakes' HR by $\sim 60 \%$. The calculated autonomic tones showed that such cardiac depression was elicited by an $\sim 80 \%$ decrease in cardiac adrenergic tone and an $\sim 620 \%$ increase in cardiac cholinergic tone - a finding that was further supported by the results of HR variability analysis.
\end{abstract}

\section{Introduction}

$\gamma$-Aminobutyric acid (GABA) is the most abundant and influential inhibitory neurotransmitter acting upon the central nervous system (CNS) of adult vertebrates (Krnjević, 1974; Olsen and Venter, 1986). It is the main mediator of neuronal excitability reduction, usually hyperpolarizing neurons by promoting an inflow of chloride ions (through $\mathrm{GABA}_{\mathrm{A}}$ receptors) or an outflow of potassium ions (through $\mathrm{GABA}_{\mathrm{B}}$ receptor) in these cells (Gähwiler and Brown, 1985; Bormann et al., 1987; Semyanov et al., 2004). Reduced concentrations of this neurotransmitter in the CNS are directly linked to the manifestation of aversive behaviors, while high concentrations are linked to relaxed states (DiScala et al., 1984; Brandão et al., 2005). The modulation of aversive behaviors and relaxation by GABA and its mimetics is of great veterinary and experimental interest, based on the search for sedative compounds with minor side effects and on the understanding of its underlying physiological mechanisms.

In vertebrates, aversive behaviors are usually followed by neurohumoral responses that stimulate both the cardiovascular and respiratory systems, preparing them for fight-or-flight situations - conversely, a relaxed state is linked to an opposite neurohumoral status. The most commonly modified cardiorespiratory variables are respiratory rate, tidal volume, heart rate (HR), myocardial contraction force, arterial blood pressure, and cardiac output (Cannon, 1929;

Abbreviations: CNS, central nervous system; CVPN, cardiac vagal preganglionic neurons; HF, high-frequency; HR, heart rate; HRV, heart rate variability; IM, intramuscular; IP,

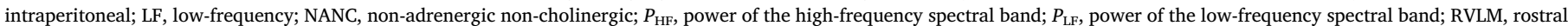
ventrolateral medulla

* Corresponding author at: Department of Zoology and Botany, São Paulo State University (UNESP), Cristóvão Colombo Street, 2265, São José do Rio Preto, SP 15054-000, Brazil.

E-mail address: luizhf@ibilce.unesp.br (L.H. Florindo).

${ }^{1}$ These authors have contributed equally to this work (Co-First Author). 
DiMicco et al., 1986; DiMicco and Abshire, 1987; Wang et al., 2001).

Virtually all vertebrates' hearts are innervated by both the sympathetic and parasympathetic subdivisions of the autonomic nervous system (Taylor et al., 2014), in which the sympathetic (adrenergic) mediators exhibit excitatory effects (e.g. elevated HR) and the parasympathetic (cholinergic) mediators exhibit inhibitory effects (e.g. reduced HR) (Nilsson, 2011; Taylor et al., 2014) - except for cyclostomes, in which adrenergic mediators exhibit inhibitory effects and cholinergic mediators exhibit excitatory effects (Augustinsson et al., 1956). In addition, it is important to note that along with the adrenergic modulation of cardiac sympathetic innervation, adrenergic stimulation from circulating adrenal catecholamines can also occur (Taylor et al., 2014). Furthermore, in some situations (e.g. postprandial state), the heart of these animals can still be subjected to excitatory or inhibitory influences from non-adrenergic and non-cholinergic factors (NANC) - such as histamine and intestinal polypeptide (Rigel, 1988; Wang et al., 2001; Skovgaard et al., 2009; Enok et al., 2012; Braga et al., 2016).

The benzodiazepine midazolam is a $\mathrm{GABA}_{\mathrm{A}}$ receptor agonist widely used (through systemic application) as a tranquilizer and sedative in both mammals and reptiles, which can also be administered in combination with anesthetic drugs for surgical procedures (Reves et al., 1985; Evans and Viola-McCabe, 1996; Mosley, 2005; Natalini, 2007; Arnett-Chinn et al., 2016). It is currently known that midazolam tends to produce small to intermediate alterations in mammalian HR (Reves et al., 1985; Natalini, 2007), however, little is known about its effects in reptiles HR. So, to fill this knowledge gap, the present study sought to verify the effects of midazolam on HR and cardiac modulation in the Burmese python (Python molurus).

The Burmese python is a representative species of the Pythonidae family, commonly used as an experimental model in comparative physiology studies, which usually investigate topics related to its ecophysiological peculiarities such as eurytopic habits (Lillywhite et al., 2012; Armelin et al., 2014; Enok et al., 2014), extra-high metabolic alterations associated with digestion and physical exercise (Secor and Diamond, 1997; Secor et al., 2000; Lignot et al., 2005; Secor, 2008; Secor and White, 2010; Enok et al., 2012), and functionally (but not anatomically) isolated pulmonary and systemic circulations (Wang et al., 2002; Wang et al., 2003; Zaar et al., 2007). Additionally, in some countries, these animals have consolidated status as a pet and is therefore involved in the pet industry's business (Snow et al., 2007; Wilson and Heinsohn, 2007; Rataj et al., 2011). For these purposes, Burmese pythons are frequently held captive, thus generating widespread demand for veterinary procedures and mechanistic physiological knowledge.

\section{Material and methods}

The present study was approved by UNESP/IBILCE Ethical Committee for Animal Research (Proc. 076/2013 CEUA), being in accordance with all the regulations and ethical guidelines in Brazil.

\subsection{Experimental animals}

Twenty-eight adult specimens of $P$. molurus (Linnaeus, 1758) were obtained from a scientific breeding center in mid-2009 (Jacarezário UNESP, Rio Claro, SP, Brazil) and reared in a serpentarium located at UNESP, São José do Rio Preto, SP, Brazil. The snakes weighed between 05 and $10 \mathrm{~kg}$ and were approximately $2.5 \mathrm{~m}$ in length. They were individually housed in 5401 plastic containers, kept at $27 \pm 1{ }^{\circ} \mathrm{C}$ (mean \pm SEM) under natural photoperiod conditions, fed laboratory rodents on a weekly basis, and given continuous access to water. The specimens' sexes were not taken into consideration, and the snakes were not fed for 15 days prior to the experiments. All experimental trials were carried out during the spring and summer seasons, from October 2012 to March 2013.

The animals were divided into four groups aiming the following purposes: determine the dose of midazolam suitable for the study $(N=12)$, verify the effects of midazolam on the animals' HR and cardiac autonomic modulation $(N=8)$, check if the recovery time given to the animals after the instrumentation was sufficient $(N=4)$, and verify whether the stress of pharmacological administrations influenced the measurements performed $(N=4)$.

\subsection{Pre-experimental procedures}

First, an inhalation mask was placed over each snake's head and perfused with isoflurane (3\%) and oxygen (97\%) until the animals became unresponsive (Mosley, 2005). Their glottis was then intubated with soft rubber tubing for the lungs to be directly ventilated with a mixture of isoflurane (1\%) and oxygen (99\%) (Mosley, 2005). The ventilation pattern was manually kept at $\sim 1.8$ breaths $\min ^{-1}$ with a tidal volume of $\sim 17.5 \mathrm{ml} \mathrm{kg}^{-1}$ by a second experimenter using an anesthesia gas blender coupled to a breathing balloon and a chronometer (Colibri Inhalatory Anesthesia Apparatus, Brasmed Veterinary Products, Paulínia, SP, Brazil) (Secor et al., 2000).

Each animal's heart was then located via palpation, and three electrocardiogram adhesive electrodes were placed around it - two of which were positioned laterally and $2 \mathrm{~cm}$ above the heart, and the third of which was placed centrally and $5 \mathrm{~cm}$ below the heart. These electrodes were connected to a BIOPAC MP36 data acquisition system (BIOPAC Systems Incorporated, Goleta, CA, USA) to continuously acquire and record the animals' electrocardiogram $(1000 \mathrm{~Hz})$, from which the HR values were derived. All aforementioned proceedings were performed in $\sim 20 \mathrm{~min}$.

The snakes were then transferred to individual 2501 plastic containers in a silent room at a temperature of $26 \pm 0.2^{\circ} \mathrm{C}$ (mean \pm SEM), in which the animals could not move excessively, thus removing the electrodes. Soon after, animals were ventilated with atmospheric air (using a manual breathing balloon at the same rate and tidal volume isoflurane was administered) and recovered awareness within $\sim 20 \mathrm{~min}$. The experiments began $2 \mathrm{~h}$ after the animals recovered awareness from the anesthesia.

\subsection{Determination of midazolam dose}

Due to the lack of information about adequate midazolam dosage for reptiles, the cardiovascular effects of three different midazolam doses were investigated using twelve snakes $\left[0.35 \mathrm{mg} \mathrm{kg}^{-1}\right.$, $0.75 \mathrm{mg} \mathrm{kg}^{-1}, 1.0 \mathrm{mg} \mathrm{kg}^{-1}$ of a $5.0 \mathrm{mg} \mathrm{ml}^{-1}$ solution; doses determined according to the suggestions of Mosley, 2005; $N=4$ for each dose tested] following the aforementioned pre-experimental procedures. For this, the animals' HR was continuously monitored for $1 \mathrm{~h}$ before and for $8 \mathrm{~h}$ after an intramuscular (IM) administration of midazolam - this monitoring period was determined to verify the time required for midazolam to exert its effects and to confirm if it persists for long-term experimental protocols. Based on the results of this test (as detailed in the Results section), the highest dose $\left(1.0 \mathrm{mg} \mathrm{kg}^{-1}\right.$ ) was chosen for use in the present study.

\subsection{Effects of midazolam on heart rate and cardiac autonomic modulation}

To verify the effects of midazolam on the animals' HR and cardiac autonomic modulation, eight animals $(N=8)$ underwent four experimental stages, with a one-month recovery period between each stage. All these experimental stages started after the completion of pre-experimental procedures.

The first stage focused on the collection of HR values until it remained stable for $30 \mathrm{~min}$ (a process that took $\sim 2 \mathrm{~h}$ ) (untreated baseline data). After this step and still as part of the first stage, the muscarinic cholinergic antagonist atropine $\left(2.5 \mathrm{mg} \mathrm{kg}^{-1}\right.$ of a $10.0 \mathrm{mg} \mathrm{ml}^{-1}$ solution) was intraperitoneally (IP) administered, and HR values were continuously collected for 1 more hour. Once the values were acquired, 
the $\beta$-adrenergic antagonist propranolol $\left(3.5 \mathrm{mg} \mathrm{kg}^{-1}\right.$ of a $10.0 \mathrm{mg} \mathrm{ml}^{-1}$ solution) was IP administered and $\mathrm{HR}$ values were once again continuously collected for $1 \mathrm{~h}$ (atropine + propranolol data).

The second stage began with an IM injection of the GABAergic agonist midazolam (1.0 $\mathrm{mg} \mathrm{kg}^{-1}$ of a $5.0 \mathrm{mg} \mathrm{ml}^{-1}$ solution) (dose determined in present study), followed by a collection of HR values until it remained stable for $30 \mathrm{~min}$ (a process which took $\sim 2 \mathrm{~h}$ ) (midazolam baseline data). Subsequently, the autonomic blockade protocol and HR collection were performed as in the first stage.

The third and fourth stages consisted of the same protocol of stages one and two, respectively, with the exception that atropine and propranolol administration order were reversed. The HR used for data analysis were the values acquired in the last minutes of stabilized data at untreated baseline, midazolam baseline and after administration of atropine, propranolol or combinations of these drugs.

Previous studies on cardiac autonomic modulation performed in $P$. molurus have already provided important information about autonomic blockades in this species (Enok et al., 2012; Armelin et al., 2014). The atropine and propranolol doses used in the present investigation were based on these studies, which also highlighted that such drugs exert their effects in $\sim 30 \mathrm{~min}$ when IP administered in P. molurus. Moreover, these studies showed that the effects of atropine and propranolol are maintained for several hours, reason why the second antagonist administration performed at the end of each experimental stage established a double autonomic blockade in the animals' hearts. It is worth noting that atropine and propranolol effects are not maintained for more than a few days (Altimiras et al., 1997), so the one-month interval between treatments is more than enough for these drugs stop exerting its effects on the cardiovascular system.

\subsection{Analysis of cardiac autonomic tones and heart rate variability}

The cardiac adrenergic and cholinergic tones were quantified for each experimental stage using the equations proposed by Altimiras et al. (1997), in order to assess the mean autonomic influence on the heart of snakes under untreated baseline and midazolam baseline conditions. To do so, the R-R intervals (60/HR; in seconds) obtained from the animals under untreated baseline condition, under midazolam baseline condition, under muscarinic cholinoceptor blockade, under the $\beta$-adrenoceptor blockade, and under both antagonists' effects were used.

HR variability (HRV) analysis was also performed for each experimental stage, according to Akselrod et al. (1981) and Altimiras (1999). For this, electrocardiogram portions of 256 cardiac cycles free of noise or respiratory artifacts were extracted from the last minutes of stabilized data at untreated baseline, midazolam baseline and after administration of atropine, propranolol or combinations of these drugs. These electrocardiogram portions were used to generate HR tachograms in the BIOPAC Student Lab Pro v3.7 software (BIOPAC Systems Incorporated, Goleta, CA, USA). In order to perform a power spectral analysis (PSA) of HR variation patterns, these tachograms were exported to text files (*.txt) and processed in the CardioSeries v2.4 software (custom software, downloadable at www.danielpenteado.com). In this software, the beat-to-beat HR series were resampled with data points every $500 \mathrm{~ms}$ by cubic spline interpolation $(2 \mathrm{~Hz})$. Next, the interpolated series were divided into half-overlapping segments of 256 points. To attenuate side effects, a Hanning window was applied and spectra were calculated for all of the segments with a discrete Fast Fourier Transformation (FFT). Then, based on the location of low-frequency (LF) and high-frequency (HF) peaks in the animals' spectra, the power of the LF $\left(P_{\mathrm{LF}}\right)$ and HF $\left(P_{\mathrm{HF}}\right)$ bands were calculated to assess sympathovagal dynamics. Because of the presence of artifacts on the electrocardiogram, HRV could not be analyzed in two of the eight animals used in the four experimental stages.

\subsection{Influence of anesthetic recovery time}

To verify if the anesthetic used in the instrumentation was exerting effect on the variables studied during the experiments, four snakes $(N=4)$ were instrumented as described in the pre-experimental procedures, with the difference that the animals were allowed to rest for $24 \mathrm{~h}$ after they recovered awareness from anesthesia. Then, HR was recorded from animals under untreated condition (during $2 \mathrm{~h}$ ), after muscarinic cholinergic blockade with atropine (during $1 \mathrm{~h}$ ), and after double autonomic blockade with atropine and propranolol (during $1 \mathrm{~h}$ ) - according to the first experimental stage. Cardiac adrenergic and cholinergic tones were also analyzed in these animals, as well as HRV (as described in Section 2.5). The results obtained in this test (24 h of post-anesthesia recovery) were later compared with those of the first experimental stage ( $2 \mathrm{~h}$ of post-anesthesia recovery).

\subsection{Saline administration test}

To check if the stress of pharmacological administrations influenced the measurements performed, four other snakes $(N=4)$ were instrumented as previously described. Two hours after anesthesia recovery, the animals' HR values were collected until HR remained stable for $30 \mathrm{~min}$. Then, to simulate the administration of midazolam, a saline solution $\left(0.9 \% ; 0.2 \mathrm{ml} \mathrm{kg}^{-1}\right)$ was IM injected and HR values were continuously recorded for a further $2 \mathrm{~h}$. Then, aiming to simulate the administration of an autonomic antagonist, the same solution $\left(0.35 \mathrm{ml} \mathrm{kg}^{-1}\right)$ was IP injected and HR was continuously collected for 1 more hour. HRV analysis was also performed on these animals (as described in Section 2.5). The results obtained before and after the saline administrations were compared to each other allowing the evaluation of possible influences of the infusions per se.

\subsection{Statistics}

The Kolmogorov-Smirnov test was applied to all of the data to verify normal distribution. Regarding the experiments on the determination of the dose of midazolam, a two-way ANOVA followed by a StudentNewman-Keuls post hoc test was used to assess significant differences between the groups' HR at different moments - before and after midazolam administrations.

Next, a one-way ANOVA for repeated measures was applied, followed by a Student-Newman-Keuls post hoc test, in order to identify differences in HR between animals under the conditions studied in all four experimental stages. Differences among cardiac adrenergic and cholinergic tones of animals under untreated baseline (first and third experimental stages) and midazolam baseline (second and fourth experimental stages) conditions were evaluated using this test as well. In addition, a one-way ANOVA for repeated measures followed by an unprotected Fisher's Least Significant Difference post hoc test was conducted in order to determine any divergences between $P_{\mathrm{LF}}$ and $P_{\mathrm{HF}}$ of animals submitted to the conditions related to all experimental stages.

The HR, cardiac autonomic tones, $P_{\mathrm{LF}}$, and $P_{\mathrm{HF}}$ obtained from animals during the first experimental stage $(2 \mathrm{~h}$ of post-anesthesia recovery) were compared to those obtained in animals that passed through $24 \mathrm{~h}$ of post-anesthesia recovery via one-way ANOVA followed by a Bonferroni post hoc.

A one-way ANOVA for repeated measures and a subsequent Student-Newman-Keuls post hoc test was performed to determine possible divergences between the animals' HR before and after the IM and IP saline administrations. Finally, the $P_{\mathrm{LF}}$ and $P_{\mathrm{HF}}$ of saline-treated animals were compared using a one-way ANOVA for repeated measures followed by an unprotected Fisher's Least Significant Difference post hoc test. A level of $P \geq 0.1$ was adopted for the normality test, and $P \leq 0.05$ was used in all the other tests. The statistical analyses mentioned above were carried out using GraphPad InStat 3.0 software 


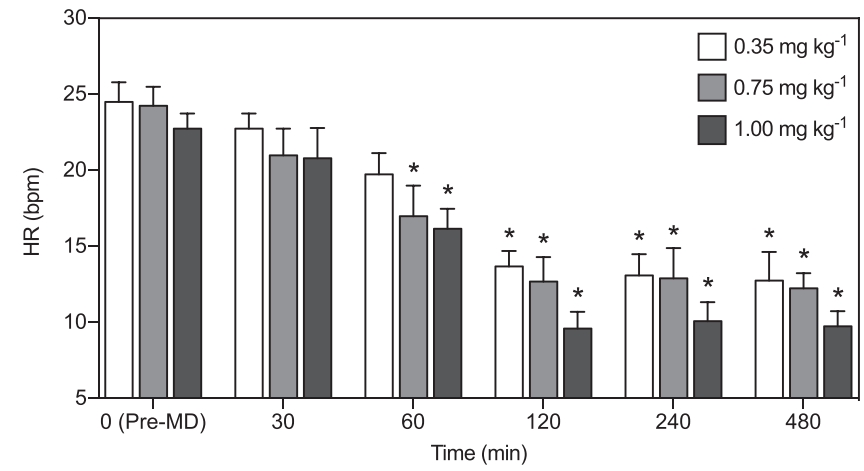

Fig. 1. Effect of different doses of midazolam on heart rate. Heart rate (HR) of Python molurus submitted to three different dosages $\left(0.35 \mathrm{mg} \mathrm{kg}^{-1}, 0.75 \mathrm{mg} \mathrm{kg}^{-1}, 1.0 \mathrm{mg} \mathrm{kg}^{-1}\right.$; $N=4$ for each dose tested) of intramuscularly-administered midazolam (MD). Data are shown as means \pm SEM. Asterisks indicate significant difference from the values observed before the administration of midazolam $(P \leq 0.05)$. No significant differences were observed between the $\mathrm{HR}$ of snakes treated with $0.30 \mathrm{mg} \mathrm{kg}^{-1}, 0.75 \mathrm{mg} \mathrm{kg}^{-1}$ and $1.00 \mathrm{mg} \mathrm{kg}^{-1}$ of midazolam.

(GraphPad Software, Inc.). All results are presented as means \pm SEM.

\section{Results}

\subsection{Determination of midazolam dose}

Prior to the administration of midazolam, the animals showed a HR of approximately $24 \mathrm{bpm}$. The administration of $0.35 \mathrm{mg} \mathrm{kg}^{-1}$ of midazolam induced significant bradycardia within $120 \mathrm{~min}$, while the administrations of $0.75 \mathrm{mg} \mathrm{kg}^{-1}$ and $1.00 \mathrm{mg} \mathrm{kg}^{-1}$ induced significant bradycardia within $60 \mathrm{~min}$ - but despite these differences, all doses tested reached their maximum effect in $120 \mathrm{~min}$ (Fig. 1). No differences were observed between the HR of snakes treated with $0.30 \mathrm{mg} \mathrm{kg}^{-1}$, $0.75 \mathrm{mg} \mathrm{kg}^{-1}$ and $1.00 \mathrm{mg} \mathrm{kg}^{-1}$ of midazolam (although the bradycardia exhibited by the animals treated with $1.00 \mathrm{mg} \mathrm{kg}^{-1}$ of midazolam appeared to be more intense) (Fig. 1), however, only the highest tested dose consistently abolished the snakes' aggressive behaviors (seen that they did not hiss or strike when they were removed from their containers at the end of the experiment). Once completely established, the effects of midazolam persisted for at least $360 \mathrm{~min}$ (Fig. 1). Therefore, based on these results, the dose of $1.0 \mathrm{mg} \mathrm{kg}^{-1}$ was considered as more adequate for use in the present study.

\subsection{Effects of midazolam on heart rate and cardiac autonomic modulation}

During the first experimental stage, the animals were found to have a HR of $24.6 \pm 0.8 \mathrm{bpm}$ (untreated baseline data), which increased to $29.1 \pm 0.7 \mathrm{bpm}$ after the administration of atropine (atropine data), and which decreased to $17.5 \pm 1.0 \mathrm{bpm}$ with the administration of propranolol (atropine + propranolol data) (Figs. 2a-c, 3a). In the second experimental stage, the snakes exhibited a HR that was significantly lower than that of animals that were not treated with the benzodiazepine $(9.7 \pm 0.6 \mathrm{bpm})$ (midazolam baseline data). This value increased to $19.2 \pm 1.5 \mathrm{bpm}$ with a muscarinic cholinoceptor blockade (midazolam + atropine data) and remained practically constant after the administration of propranolol $(16.0 \pm 0.4 \mathrm{bpm})$ (midazolam + atropine + propranolol data) (Figs. 2d-f, 3b).

In the third experimental stage, the snakes presented an initial HR of $25.3 \pm 0.6 \mathrm{bpm}$ (untreated baseline data), which decreased to $16.5 \pm 1.2 \mathrm{bpm}$ after the infusion of propranolol (propranolol data), and which did not change with the administration of atropine (18.4 $\pm 0.8 \mathrm{bpm}$ ) (propranolol + atropine data) (Figs. 2g-i, 3c). During the fourth experimental stage, the snakes exhibited a HR of $9.9 \pm 0.7 \mathrm{bpm}$ (midazolam baseline data), which remained virtually constant after the administration of propranolol (10.0 $\pm 0.5 \mathrm{bpm})$ (midazolam + propranolol data), and which increased to $16.5 \pm 1.0 \mathrm{bpm}$ after the infusion of atropine (midazolam + propranolol + atropine data) (Figs. 2j-1, 3d).

In the experimental protocols in which atropine was administered before propranolol, the snakes that did not receive midazolam (first experimental stage) exhibited a cardiac adrenergic tone of $39.7 \pm 2.9 \%$ and a cardiac cholinergic tone of $11.3 \pm 1.6 \%$ (Fig. $4 a$ ), values which changed to $13.7 \pm 5.6 \%$ and $81.5 \pm 8.1 \%$, respectively, after the administration of midazolam in the second experimental stage (Fig. 4b). As for the experimental protocols in which propranolol was administered before atropine, the animals that did not receive midazolam (third experimental stage) exhibited a cardiac adrenergic tone of $40.6 \pm 5.1 \%$ and a cardiac cholinergic tone of $13.5 \pm 4.2 \%$ (Fig. 4c), which changed to $-5.6 \pm 7.9$ and $64.7 \pm 8.3 \%$, respectively, after receiving midazolam in the fourth experimental stage (Fig. 4d).

Regarding PSA, the spectra that describe the animals' HR variation patterns were essentially below $0.10 \mathrm{~Hz}$ in all conditions studied (Fig. 5), presenting two remarkable frequency peaks that were used to define the LF and HF spectral areas that allowed the calculation of $P_{\mathrm{LF}}$ $(0.00 \mathrm{~Hz}-0.05 \mathrm{~Hz})$ and $P_{\mathrm{HF}}(0.05 \mathrm{~Hz}-0.10 \mathrm{~Hz})$ for all animals (Fig. 6). In the first experimental stage, the snakes exhibited a major LF peak between $0.00 \mathrm{~Hz}$ and $0.05 \mathrm{~Hz}$ and a minor HF peak between $0.05 \mathrm{~Hz}$ and $0.10 \mathrm{~Hz}$ (untreated baseline data) (Figs. 5a, 6a). After muscarinic cholinergic blockade with atropine, the spectral area of the LF peak was considerably reduced while the HF peak disappeared (atropine data) (Figs. 5b, 6b). The establishment of a double autonomic blockade with the administration of propranolol eliminated the remaining area of the LF peak - virtually eradicating the spectral densities of all snakes (atropine + propranolol data) (Figs. 5c, 6c). In the second experimental stage, with the administration of midazolam, the snakes' LF and HF peaks increased substantially, but no change occurred to their locations in the spectra nor to the animals' mean $P_{\mathrm{HF}}$ (midazolam baseline data) (Figs. 5d, 6d). The administration of atropine reduced both LF and HF peaks to zero (midazolam + atropine data) (Figs. 5e, 6e), which remained unchanged after the administration of propranolol (midazolam + atropine + propranolol data) (Figs. 5f, 6f).

Prior to pharmacological administrations, the spectra observed in the animals during the third experimental stage were very similar to those observed in the animals during the first experimental stage (untreated baseline data) (Figs. $5 \mathrm{~g}, 6 \mathrm{~g}$ ). After $\beta$-adrenergic blockade with propranolol, the spectral area of the LF peak decreased while the area of the HF peak remained practically unchanged (propranolol data) (Figs. 5h, 6h). The subsequent administration of atropine completely extinguished the snakes' spectral densities (propranolol + atropine data) (Figs. 5i, 6i). Finally, during the fourth experimental stage, midazolam changed the LF and HF peaks (and $P_{\mathrm{LF}}$ and $P_{\mathrm{HF}}$ ) as in the second experimental stage (midazolam baseline data) (Figs. 5j, 6j). The administration of propranolol reduced the LF peak and did not significantly alter the HF peak (midazolam + propranolol data) (Figs. 5k, $6 \mathrm{k}$ ), which were both abolished by the administration of atropine (midazolam + propranolol + atropine data) (Figs. 5l, 6l).

\subsection{Influence of anesthetic recovery time}

The HR, cardiac autonomic tones, $P_{\mathrm{LF}}$, and $P_{\mathrm{HF}}$ obtained from animals that underwent a $24 \mathrm{~h}$ period of post-anesthesia recovery are shown in Table 1. No significant difference in any variable was detected between these animals and those that passed through the first experimental stage ( $2 \mathrm{~h}$ of post-anesthesia recovery).

\subsection{Saline administration test}

The results of saline experiments (HR, $P_{\mathrm{LF}}$ and $P_{\mathrm{HF}}$ ) are shown in Table 2. No significant difference was detected between any variable observed in the snakes before and after the IM and IP saline 

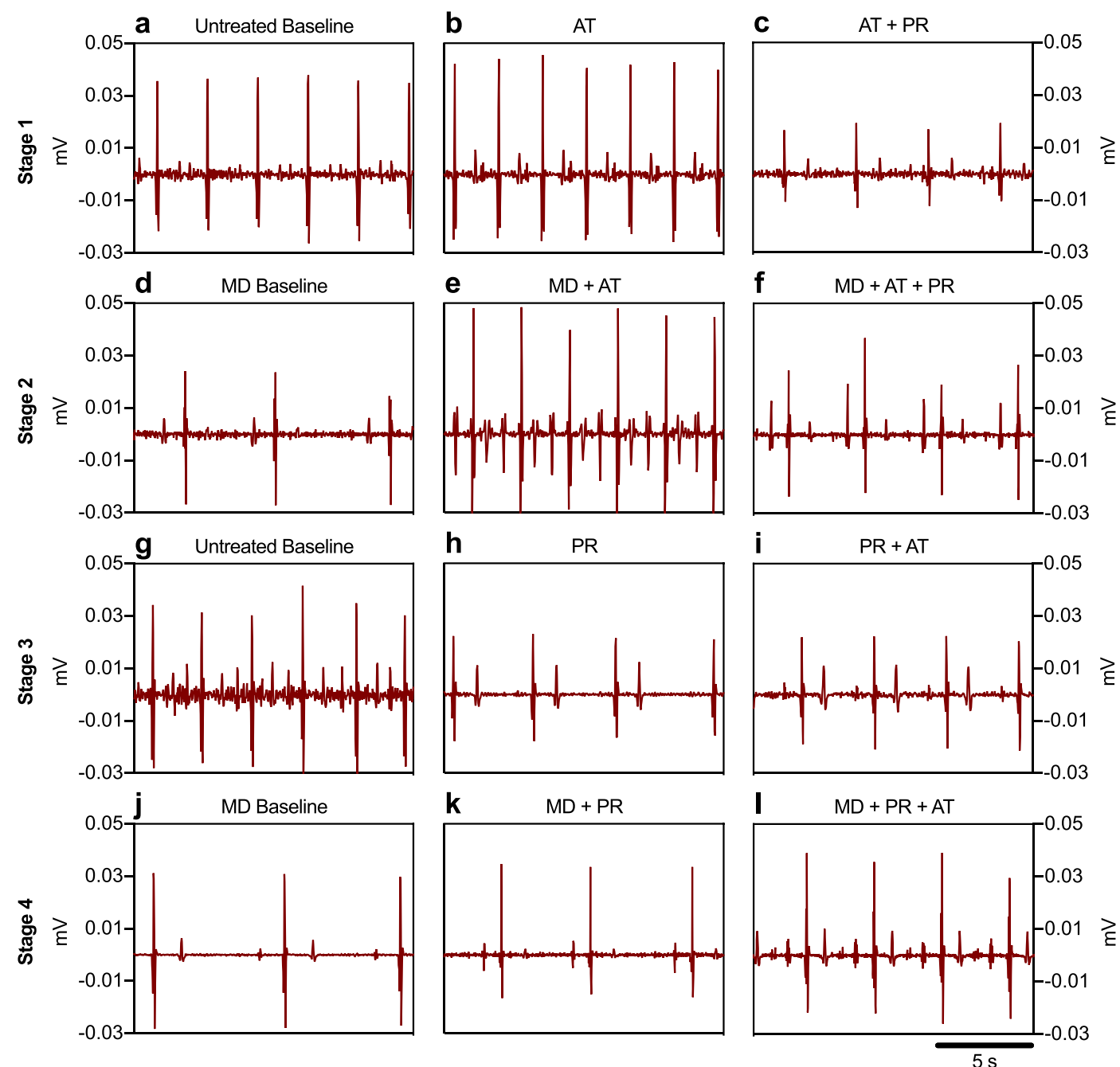

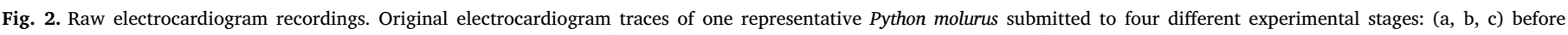

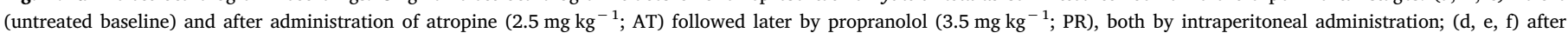

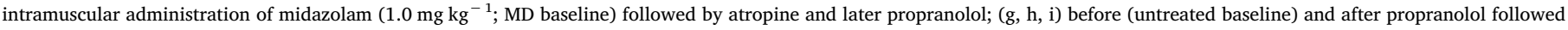

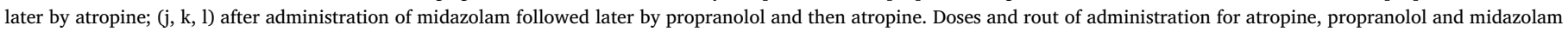
were the same in all treatments.

administrations.

\section{Discussion}

Initially, it was possible to observe that the HR levels found in the present study in untreated and autonomically blocked P. molurus are consistent with those previously found by other authors (Secor et al., 2000; Enok et al., 2012; Armelin et al., 2014) (Figs. 1, 3a, c). In addition, our results show that midazolam strongly influences the snakes' HR (average values were reduced by $\sim 60 \%$ ) (Figs. $3 \mathrm{~b}, \mathrm{~d}$ ).

Because the HR of ectothermic vertebrates can respond either to classic autonomic neurotransmitters (adrenaline/noradrenaline and acetylcholine) (Leite et al., 2009; Armelin et al., 2014; Taylor et al., 2014; Teixeira et al., 2015) or to non-adrenergic non-cholinergic factors (Wang et al., 2001; Skovgaard et al., 2009; Enok et al., 2012; Braga et al., 2016), it seems difficult to determine the mediators of this case of bradycardia. However, the lack of significant differences among the HR levels of double blocked animals in the four experimental stages performed (Fig. 3a-d) is evidence that midazolam influences this variable through changes in cardiac adrenergic and cholinergic tones (i.e. midazolam does not influence intrinsic heart rate). If this bradycardia were directly triggered by the benzodiazepine molecule or by NANC factors, the HR of double-blocked snakes treated with midazolam would be lower than that of double-blocked snakes without midazolam treatment. This is an interesting finding, seen that it can be deduced that such cardiovascular depression can simply be reversed by autonomic antagonists in these animals.

The cardiac autonomic tones found in $P$. molurus specimens that did not receive midazolam treatment are consistent with those reported by Armelin et al. (2014). Our results indicate that the effects of midazolam on HR were elicited by an $\sim 80 \%$ reduction in cardiac adrenergic tone and an $\sim 620 \%$ elevation in cardiac cholinergic tone (Fig. 4a-d). Several studies have found that the order of pharmacological manipulation with atropine and propranolol may affect the animals' calculated cardiac autonomic tones, especially when propranolol is administered prior to atropine (Rosenbluth and Simeone, 1934; Altimiras et al., 1997; Wang et al., 2001). This phenomenon occurs because propranolol is a non-selective $\beta$-blocker that promotes less specific cardiovascular effects, which in turn tends to induce parasympathetic reflex changes in HR to compensate such effects - resulting in an altered calculated cardiac cholinergic tone (Altimiras et al., 1997). Nevertheless, differently from observations in other species (Rosenbluth and Simeone, 1934; Altimiras et al., 1997; Wang et al., 2001), our results revealed that the administration order of atropine and propranolol did not influence the calculated cardiac autonomic tones exhibited by $P$. molurus (Fig. 4a-d). 

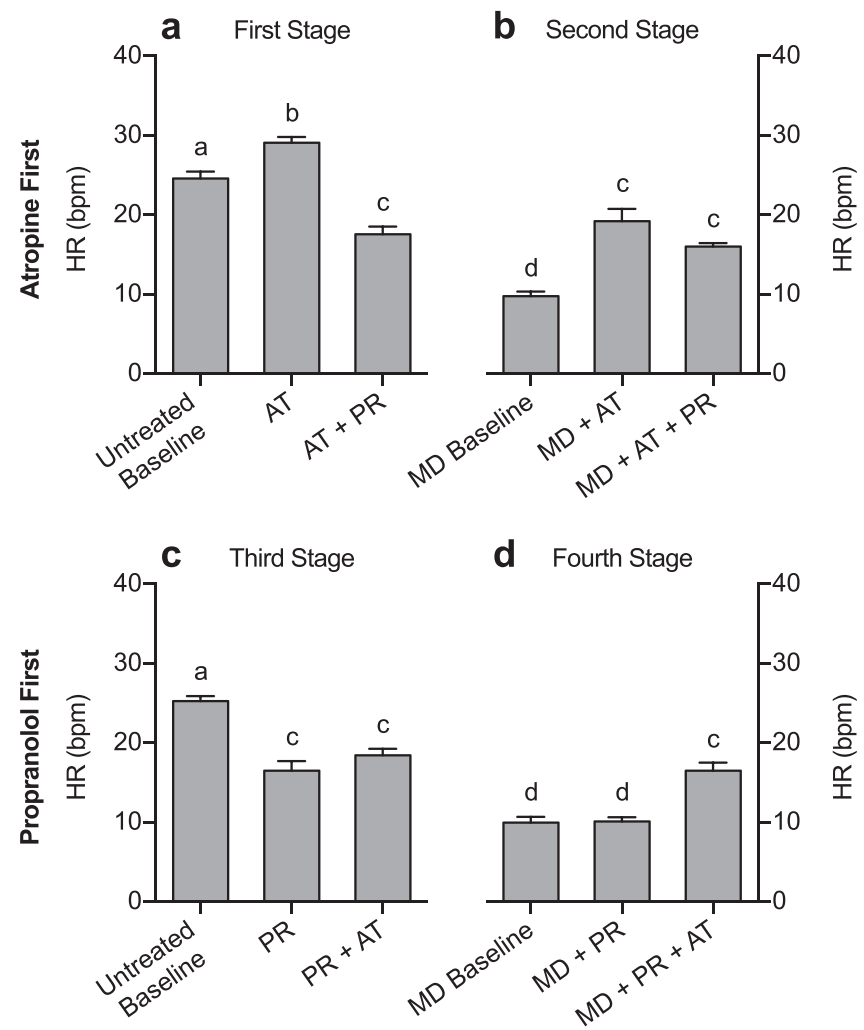

Fig. 3. Heart rate during all experimental stages. Heart rate (HR) of Python molurus $(N=8)$ submitted to four different experimental stages: (a) before (untreated baseline) and after administration of atropine $\left(2.5 \mathrm{mg} \mathrm{kg}^{-1}\right.$; AT) followed later by propranolol (3.5 $\mathrm{mg} \mathrm{kg}^{-1}$; PR), both by intraperitoneal administration; (b) after intramuscular administration of midazolam (1.0 $\mathrm{mg} \mathrm{kg}^{-1}$; MD baseline) followed by atropine and later propranolol; (c) before (untreated baseline) and after propranolol followed later by atropine; (d) after administration of midazolam followed later by propranolol and then atropine. Doses and rout of administration for atropine, propranolol and midazolam were the same in all treatments. Data are shown as means \pm SEM. Values that do not share a superscript letter differ significantly $(P \leq 0.05)$.

The HRV analysis, when performed using a small number of cardiac cycles, allows the investigation of the animals' instantaneous HR oscillations in order to assess their sympathovagal dynamics. These oscillations are essentially generated by classic autonomic neurotransmitters or NANC factors secreted by nerve endings (Akselrod et al., 1981; Altimiras, 1999; Campbell et al., 2006; Li et al., 2006; Zaccone et al., 2011), given that humoral factors (e.g. circulating catecholamines and hormones) are unable to produce such rapid HR oscillations to appear in this analysis (Altimiras, 1999). Thus, considering that the administration of atropine abolishes cardiac cholinergic tone, the decrease in $P_{\mathrm{LF}}$ and the eradication of $P_{\mathrm{HF}}$ induced by this antagonist are evidence that the LF HR oscillations are of sympathetic and parasympathetic origin and the HF HR oscillations are exclusively of parasympathetic origin (untreated baseline data; atropine data) (Figs. 5a, b, $6 \mathrm{a}, \mathrm{b})$. The data on the administration of propranolol corroborate this observation, seen that this $\beta$-adrenergic antagonist also reduced $P_{\mathrm{LF}}$ but did not induce modifications in $P_{\mathrm{HF}}$ (untreated baseline data; propranolol data) (Figs. 5g, h, 6g, h). The autonomic origin of these LF and HF HR oscillations are similar to those found in other species of vertebrates (Akselrod et al., 1981; Kuwahara et al., 1994; Montano et al., 1994; De Vera and González, 1997; Braga et al., 2016; Carravieri et al., 2016), and appears to be an evolutionarily conserved trait in this group of animals.

The increase in $P_{\mathrm{LF}}$ observed in snakes under midazolam baseline condition was probably mediated by the parasympathetic subdivision of the autonomic nervous system, seen that midazolam induced a large increase in the animals' cardiac cholinergic tone (Fig. 4a-d). This
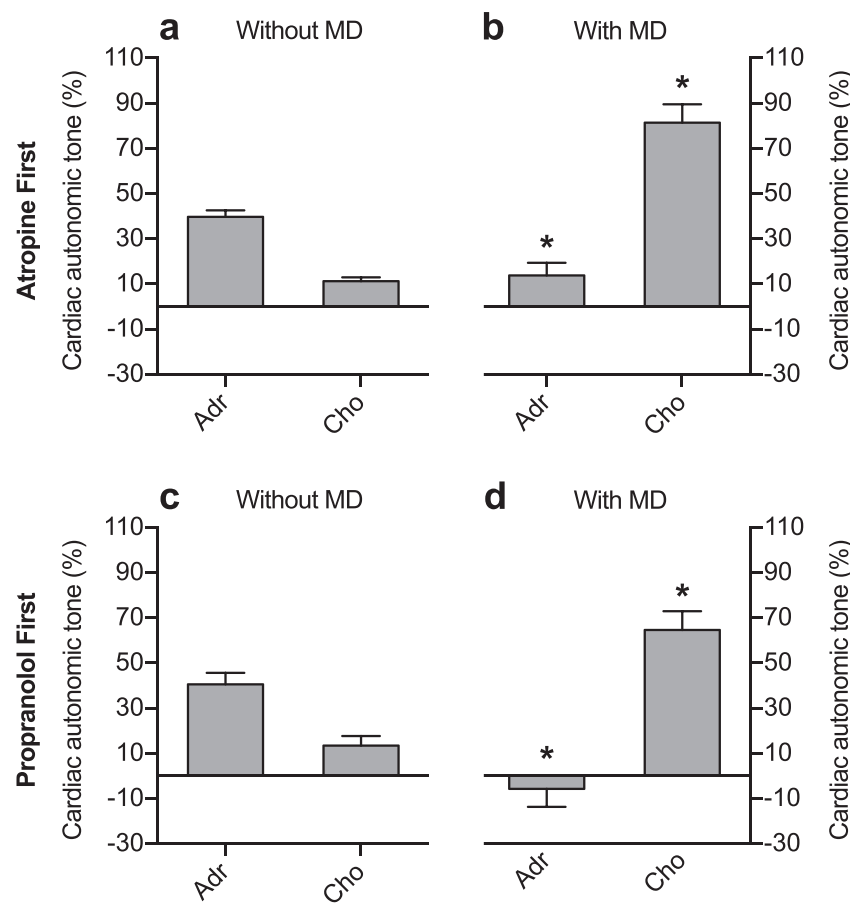

Fig. 4. Effect of midazolam on cardiac autonomic tones. Calculated cardiac adrenergic (Adr) and cholinergic (Cho) tones of Python molurus $(N=8)$ that underwent the (a) first (without midazolam; MD; atropine first), (b) second (with MD; atropine first), (c) third (without MD; propranolol first) and (d) fourth (with MD; propranolol first) experimental stages. Data are shown as means \pm SEM. Asterisks indicate significant differences from the same type of tone expressed by animals that were not treated with midazolam in the same autonomic blockade protocol $(P \leq 0.05)$. No significant differences in autonomic tones were derived from the inversion of pharmacological manipulations.

observation is supported by the fact that, when the snakes were under the effects of midazolam, the administration of atropine (midazolam baseline data; midazolam + atropine data) (Figs. 5d, e, 6d, e) promoted a greater reduction in $P_{\mathrm{LF}}$ compared to the administration of propranolol (midazolam baseline data; midazolam + propranolol data) (Figs. 5j, k, 6j, k) - which did not occur in animals that were not under the effects of this benzodiazepine (untreated baseline data; atropine data; propranolol data) (Figs. 5a, b, g, h, 6a, b, g, h). As the administration of midazolam also triggered a drastic reduction in the snakes' cardiac adrenergic tone (Fig. 4a-d), such incipient sympathetic role in the mediation of HR oscillations of midazolam-treated animals was expected. The complete elimination of $P_{\mathrm{LF}}$ and $P_{\mathrm{HF}}$ that occurred in double blocked animals, in all studied experimental stages (atropine + propranolol data; midazolam + atropine + propranolol data; propranolol + atropine data; midazolam + propranolol + atropine data) (Figs. 5c, f, i, 1, 6c, f, i, 1), indicates that nerve-secreted NANC factors have no participation in the mediation of short-term HR fluctuations in $P$. molurus that were and were not treated with midazolam - confirming the adrenergic and cholinergic nature of these benzodiazepine-induced changes in HR.

It is important to emphasize that our methodology allowed for the calculation of cardiac adrenergic tone, and not of cardiac sympathetic tone. As discussed by Altimiras et al. (1997), cardiac sympathetic tone refers only to the activity of sympathetic innervation on the heart whereas cardiac adrenergic tone refers to such activity plus the effect of circulating catecholamines from adrenal glands. As our methods involved the blockade of $\beta$-adrenergic receptors with propranolol, it was not possible to determine whether the animals' cardiac adrenergic stimulation was derived from direct sympathetic nervous activity, from circulating catecholamines, or both. However, the analysis of HRV can provide clues about the origins of the cardiac adrenergic stimulation.

Given the fact that only short-term HR oscillations appear in our 

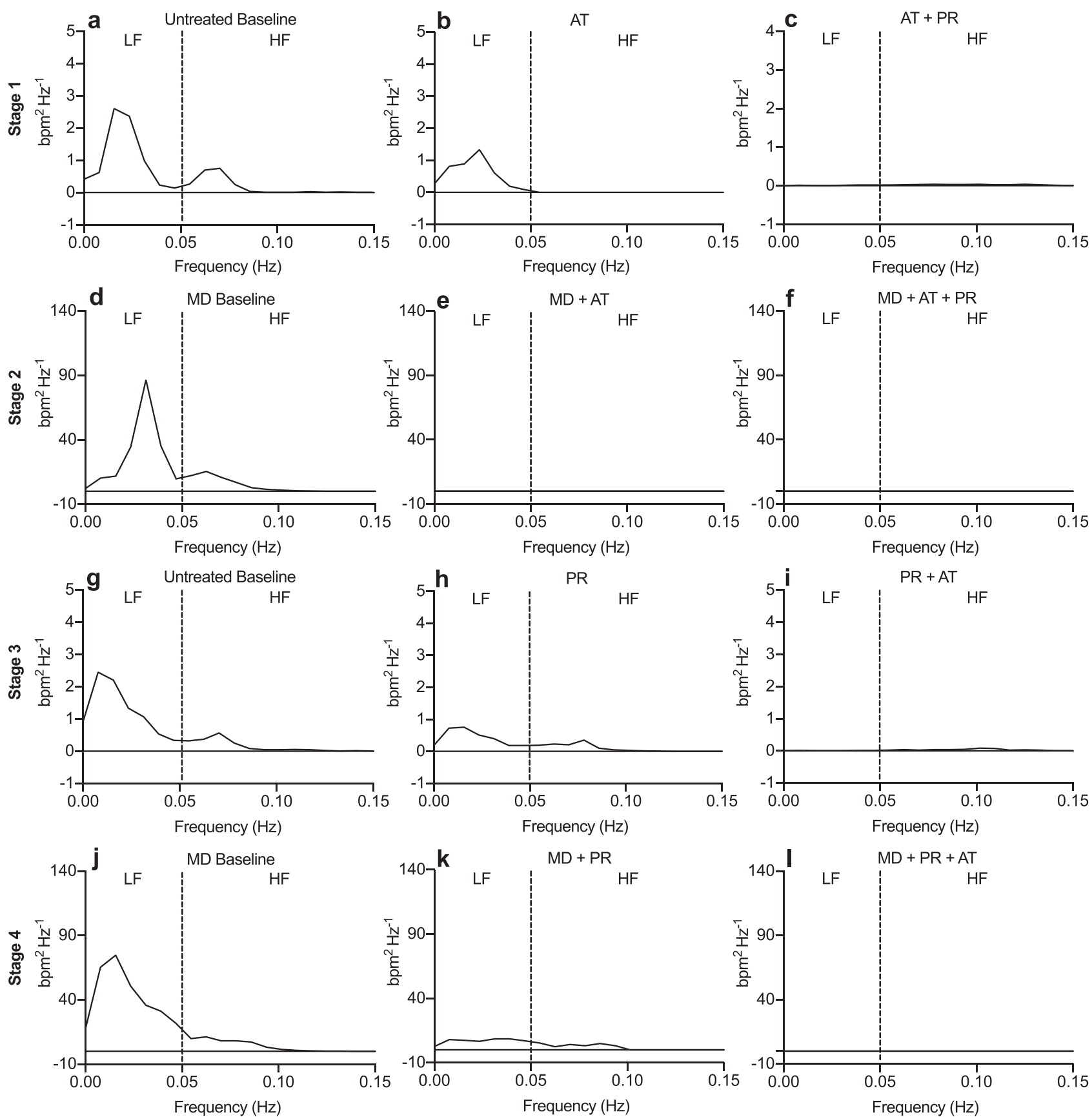

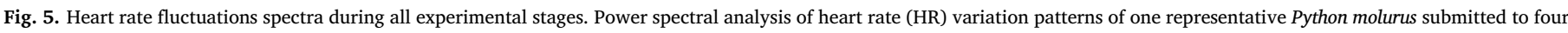

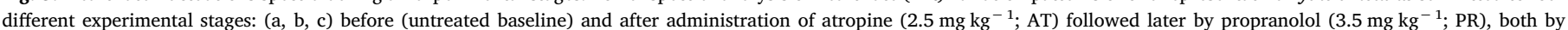

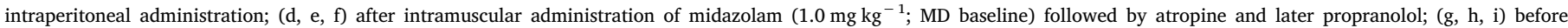

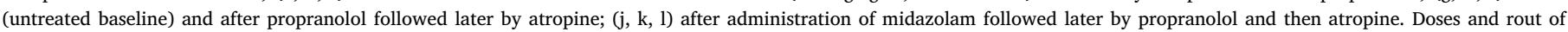

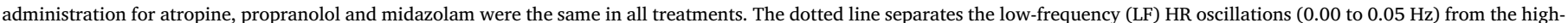
frequency (HF) HR oscillations ( 0.05 to $0.10 \mathrm{~Hz}$ ).

HRV analysis (Altimiras, 1999), it can be inferred that the cardiac adrenergic tone of $P$. molurus that were not treated with midazolam is, at least partially, derived from sympathetic nervous activity on the heart - seen that the beat-to-beat HR oscillations observed in these animals were not eradicated by muscarinic cholinergic blockade (Figs. 5a, b, 6a, b). Conversely, in midazolam-treated snakes, the remaining cardiac adrenergic tone is probably derived from circulating catecholamines from adrenal glands, as the administration of atropine abolished all short-term HR oscillations in these animals (Figs. 5d, e, $6 \mathrm{~d}, \mathrm{e})$. Also, it is conceivable that the remaining cardiac adrenergic tone of midazolam-treated snakes has been maintained by catecholamines that were already present in the animals' blood prior to the administration of the benzodiazepine.

As midazolam was systemically administered in the present study, one must keep in mind that it can stimulate $\mathrm{GABA}_{\mathrm{A}}$ receptors in both central and peripheral nervous systems, and being so, the neural pathways involved in the modulation of cardiac autonomic control that were affected by this benzodiazepine cannot be clearly specified.

Previous studies in mammals have shown that hypothalamic stimulation (specially of the hypothalamic defense area) triggers an excitation of the sympathomodulatory rostral ventrolateral medulla (RVLM) and an inhibition of the cardiac vagal preganglionic neurons 

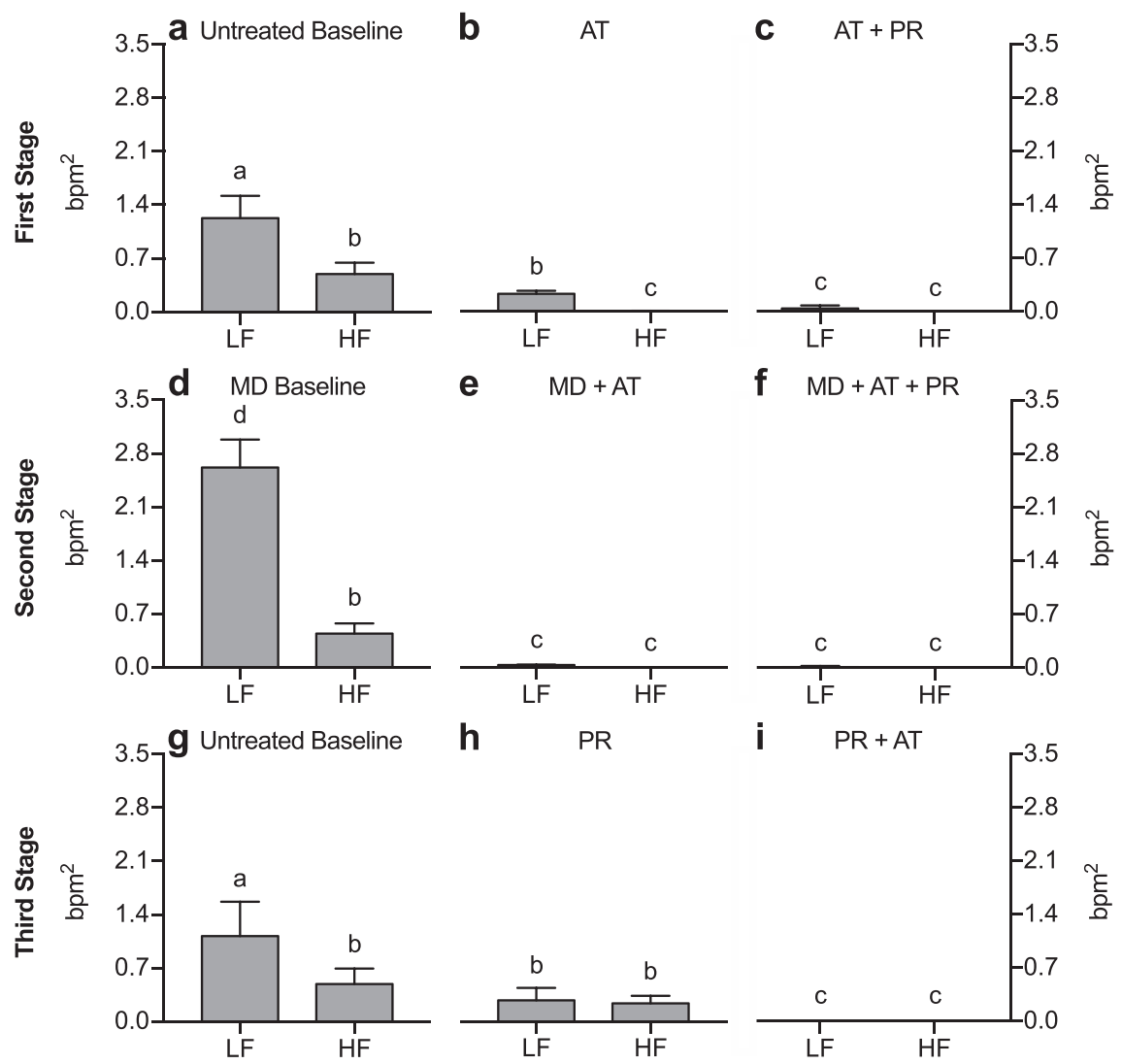

h
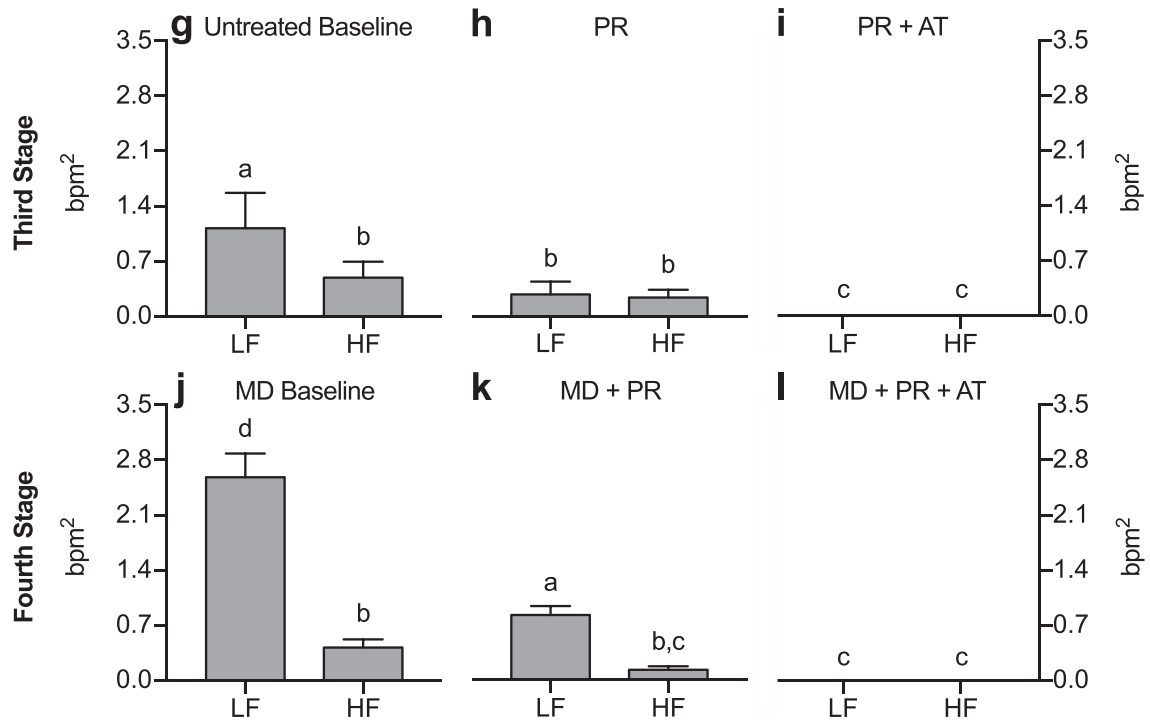

Fig. 6. Power of the heart rate fluctuations spectra during all experimental stages. Power of the low-frequency (LF) and highfrequency (HF) heart rate variability spectral bands of Python molurus $(N=6)$ submitted to four different experimental stages: ( $a, b, c)$ before (untreated baseline) and after administration of atropine $\left(2.5 \mathrm{mg} \mathrm{kg}^{-1}\right.$; AT) followed later by propranolol (3.5 $\mathrm{mg} \mathrm{kg}^{-1}$; PR), both by intraperitoneal administration; (d, e, f) after intramuscular administration of midazolam (1.0 $\mathrm{mg} \mathrm{kg}^{-1}$; MD baseline) followed by atropine and later propranolol; ( $\mathrm{g}, \mathrm{h}, \mathrm{i})$ before (untreated baseline) and after propranolol followed later by atropine; ( $, \mathrm{k}, \mathrm{l})$ after administration of midazolam followed later by propranolol and then atropine. Doses and rout of administration for atropine, propranolol and midazolam were the same in all treatments. Data are shown as means \pm SEM. Values that do not share a superscript letter differ significantly $(P \leq 0.05)$.
(CVPN), that respectively leads to an increase in cardiac adrenergic tone and a decrease in cardiac cholinergic tone, generating tachycardia (Djojosugito et al., 1970; Gebber and Snyder, 1970; Kylstra and Lisander, 1970; Barman and Gebber, 1979; Coote et al., 1979; Taylor et al., 1999). On the other hand, hypothalamic lesions promote a decrease in cardiac sympathetic activity associated with an increase in cardiac vagal activity, generating bradycardia (Lopes and Palmer, 1978; Taylor et al., 1999). Thus, taking into account that the neural networks related to cardiovascular control are well conserved in vertebrates (Taylor et al., 1999; Nilsson, 2011; Zena et al., 2013; Taylor et al., 2014), and that the hypothalamus and the RVLM express large amounts of $\mathrm{GABA}_{\mathrm{A}}$ receptors (Decavel and Van den Pol, 1990; Schreihofer and Guyenet, 2002), it can be speculated that the systemic administration of midazolam inhibited these areas of the snakes' CNS, resulting in the decreased cardiac adrenergic tone and increased cardiac cholinergic tone (Fig. 4a-d) that caused the profound bradycardic response observed in the present study (Fig. 3a-d).

Finally, the presence of GABA receptors in the peripheral autonomic nervous system has already been documented. It is currently known that sympathetic peripheral ganglion cells express $\mathrm{GABA}_{\mathrm{A}}$ receptors, which usually promote a cellular outflow rather than an inflow of chloride ions when stimulated, and therefore have excitatory effect eliciting noradrenalin secretion on the heart and consequently tachycardia (De Groat, 1970; Bowery and Brown, 1974; Adams and Brown,
1975; Ong and Kerr, 1990). Moreover, there is evidence for the presence of bicuculline-insensitive $\mathrm{GABA}_{\mathrm{B}}$ receptors with inhibitory effect in sympathetic nerve terminals, which can trigger a reduction of cardiac adrenergic tone and bradycardia when stimulated (Bowery et al., 1981; Ong and Kerr, 1990). Similarly, peripheral parasympathetic cells also seem to express excitatory $\mathrm{GABA}_{A}$ receptors and inhibitory $\mathrm{GABA}_{\mathrm{B}}$ receptors that correspondingly stimulate and suppress neuronal acetylcholine release (Ong and Kerr, 1990; Blackshaw et al., 2000; Partosoedarso et al., 2001). Thus, if mammals and reptiles share these characteristics, it is unlikely that the administration of midazolam reduced cardiac adrenergic tone in $P$. molurus through peripheral autonomic pathways, seen that benzodiazepines do not interact with $\mathrm{GABA}_{\mathrm{B}}$ receptors. However, the administration of midazolam may have stimulated $\mathrm{GABA}_{\mathrm{A}}$ receptors in peripheral parasympathetic neurons, leading to the observed increased cardiac cholinergic tone (and bradycardia).

\section{Conclusions}

Given the results presented herein, we conclude that a systemic administration of the $\mathrm{GABA}_{\mathrm{A}}$ receptor agonist midazolam elicits significant bradycardia in $P$. molurus, which is determined by a benzodiazepine-induced decrease in cardiac adrenergic tone and increase in cardiac cholinergic tone, and not by a direct action of this drug on the 
Table 1

Heart rate (HR), cardiac autonomic tones, power of the low-frequency spectral band $\left(P_{\mathrm{LF}}\right)$ and power of the high-frequency spectral band $\left(P_{\mathrm{HF}}\right)$ of animals that passed through $24 \mathrm{~h}$ of post-anesthesia recovery and animals that passed through $2 \mathrm{~h}$ of post-anesthesia recovery (submitted to the first experimental stage).

\begin{tabular}{|c|c|c|}
\hline & $\begin{array}{l}\text { Animals } 24 \mathrm{~h} \text { after } \\
\text { anesthesia recovery }\end{array}$ & $\begin{array}{l}\text { Animals } 2 \mathrm{~h} \text { after } \\
\text { anesthesia recovery }\end{array}$ \\
\hline $\begin{array}{l}\text { Untreated baseline HR } \\
\text { (bpm) }\end{array}$ & $24.2 \pm 0.2$ & $24.6 \pm 0.8$ \\
\hline Atropine HR (bpm) & $33.0 \pm 1.3$ & $29.1 \pm 0.7$ \\
\hline $\begin{array}{l}\text { Atropine + propranolol HR } \\
\quad(\mathrm{bpm})\end{array}$ & $20.6 \pm 1.3$ & $17.5 \pm 1.0$ \\
\hline Cardiac adrenergic tone (\%) & $37.2 \pm 4.2$ & $39.7 \pm 2.9$ \\
\hline $\begin{array}{l}\text { Cardiac cholinergic tone } \\
\text { (\%) }\end{array}$ & $22.3 \pm 3.2$ & $11.3 \pm 1.6$ \\
\hline $\begin{array}{l}\text { Untreated baseline } P_{\mathrm{LF}} \\
\quad\left(\mathrm{bpm}^{2}\right)\end{array}$ & $1.76 \pm 0.14$ & $1.22 \pm 0.29$ \\
\hline $\begin{array}{l}\text { Untreated baseline } P_{\mathrm{HF}} \\
\quad\left(\mathrm{bpm}^{2}\right)\end{array}$ & $0.78 \pm 0.16$ & $0.49 \pm 0.15$ \\
\hline Atropine $P_{\mathrm{LF}}\left(\mathrm{bpm}^{2}\right)$ & $0.14 \pm 0.05$ & $0.23 \pm 0.04$ \\
\hline Atropine $P_{\mathrm{HF}}\left(\mathrm{bpm}^{2}\right)$ & $0.02 \pm 0.01$ & $0.00 \pm 0.00$ \\
\hline $\begin{array}{l}\text { Atropine }+ \text { propranolol } P_{\mathrm{LF}} \\
\quad\left(\mathrm{bpm}^{2}\right)\end{array}$ & $0.00 \pm 0.00$ & $0.00 \pm 0.00$ \\
\hline $\begin{array}{l}\text { Atropine }+ \text { propranolol } P_{\mathrm{HF}} \\
\quad\left(\mathrm{bpm}^{2}\right)\end{array}$ & $0.00 \pm 0.00$ & $0.00 \pm 0.00$ \\
\hline
\end{tabular}

Values presented as means \pm SEM. Unpaired data. No significant differences were detected between animals that passed through $24 \mathrm{~h}$ of post-anesthesia recovery and animals that passed through $2 \mathrm{~h}$ of post-anesthesia recovery.

Table 2

Heart rate (HR), power of the low-frequency spectral band $\left(P_{\mathrm{LF}}\right)$ and power of the highfrequency spectral band $\left(P_{\mathrm{HF}}\right)$ of Python molurus during untreated baseline conditions, treated with intramuscular (IM) saline solution, and treated with intraperitoneal (IP) saline solution.

\begin{tabular}{llll}
\hline & $\begin{array}{l}\text { Before saline } \\
\text { administrations }\end{array}$ & $\begin{array}{l}\text { After IM saline } \\
\text { administration }\end{array}$ & $\begin{array}{l}\text { After IP saline } \\
\text { administration }\end{array}$ \\
\hline $\mathrm{HR}(\mathrm{bpm})$ & $23.6 \pm 1.3$ & $24.1 \pm 0.6$ & $23.4 \pm 0.4$ \\
$P_{\mathrm{LF}}\left(\mathrm{bpm}^{2}\right)$ & $0.95 \pm 0.83$ & $1.43 \pm 0.74$ & $1.24 \pm 0.35$ \\
$P_{\mathrm{HF}}\left(\mathrm{bpm}^{2}\right)$ & $0.41 \pm 0.38$ & $0.67 \pm 0.52$ & $0.33 \pm 0.17$ \\
\hline
\end{tabular}

Values presented as means \pm SEM. Paired data. No significant differences were found between any variable observed in the snakes before and after the IM and IP saline administrations.

animals' hearts.

\section{Acknowledgements}

We are grateful to Professor Ruy Campos (associate editor of Autonomic Neuroscience: Basic and Clinical) and an anonymous reviewer for the valuable comments and suggestions on an earlier version of the manuscript, as well as the members of Florindo's Laboratory for the assistance with the animal care.

\section{Funding}

This study was supported by the Brazilian National Council for Scientific and Technological Development (CNPq) and the São Paulo Research Foundation (FAPESP), through the Brazilian National Institute of Science and Technology in Comparative Physiology (INCT-FisC) [grant number 08/57712-4].

\section{References}

Adams, P.R., Brown, D.A., 1975. Actions of $\gamma$-aminobutyric acid on sympathetic ganglion cells. J. Physiol. 250, 85-120.

Akselrod, S., Gordon, D., Ubel, F.A., Shannon, D.C., Berger, A.C., Cohen, R.J., 1981.

Power spectrum analysis of heart rate fluctuation: a quantitative probe of beat-tobeat cardiovascular control. Science 213, 220-222.

Altimiras, J., 1999. Understanding autonomic sympathovagal balance from short-term heart-rate variations. Are we analyzing noise? Comp. Biochem. Physiol. 124A, $447-460$.

Altimiras, J., Aissaoui, A., Tort, L., Axelsson, M., 1997. Cholinergic and adrenergic tones in the control of heart rate in teleosts. How should they be calculated? Comp. Biochem. Physiol. 118A, 131-139.

Armelin, V.A., Braga, V.H.S., Abe, A.S., Rantin, F.T., Florindo, L.H., 2014. Autonomic control of heart rate during orthostasis and the importance of orthostatic-tachycardia in the snake Python molurus. J. Comp. Physiol. 184B, 903-912.

Arnett-Chinn, E.R., Hadfield, C.A., Clayton, L.A., 2016. Review of intramuscular midazolam for sedation in reptiles at the National Aquarium, Baltimore. J. Herpetol. Med. Surg. 26, 59-63.

Augustinsson, K.B., Fänge, R., Johnels, A., Östlund, E., 1956. Histological, physiological and biochemical studies on the heart of two cyclostomes, hagfish (Myxine) and lamprey (Lampetra). J. Physiol. 131, 257-276.

Barman, S.M., Gebber, G.L., 1979. Picrotoxin- and bicuculline-sensitive inhibition of cardiac vagal reflexes. J. Pharmacol. Exp. Ther. 209, 67-72.

Blackshaw, L.A., Smid, S.D., O'Donnell, T.A., Dent, J., 2000. GABAB receptor-mediated effects on vagal pathways to the lower oesophageal sphincter and heart. Br. J. Pharmacol. 130, 279-288.

Bormann, J., Hamill, O.P., Sakmann, B., 1987. Mechanism of anion permeation through channels gated by glycine and $\gamma$-aminobutyric acid in mouse cultured spinal neurones. J. Physiol. 385, 243-286.

Bowery, N.G., Brown, D.A., 1974. Depolarizing actions of $\gamma$-aminobutyric acid and related compounds on rat superior cervical ganglia in vitro. Br. J. Pharmacol. 50, 205-218.

Bowery, N.G., Doble, A., Hill, D.R., Hudson, A.L., Shaw, J.S., Turnbull, M.J., Warrington, R., 1981. Bicuculline-insensitive GABA receptors on peripheral autonomic nerve terminal. Eur. J. Pharmacol. 71, 53-70.

Braga, V.H.S., Armelin, V.A., Teixeira, M.T., Abe, A.S., Rantin, F.T., Florindo, L.H., 2016 The effects of feeding on cardiac control of the broad-nosed caiman (Caiman latirostris): the role of the autonomic nervous system and NANC factors. J. Exp. Zool. 325, 524-531.

Brandão, M.L., Borelli, K.G., Nobre, M.J., Santos, J.M., Albrechet-Souza, L., Oliveira, A.R., Martinez, R.C., 2005. GABAergic regulation of the neural organization of fear in the midbrain tectum. Neurosci. Biobehav. Rev. 29, 1299-1311.

Campbell, H.A., Leite, C.A.C., Wang, T., Skals, M., Abe, A.S., Egginton, S., Rantin, F.T., Bishop, C.M., Taylor, E.W., 2006. Evidence for a respiratory component, similar to mammalian respiratory sinus arrhythmia, in the heart rate variability signal from the rattlesnake, Crotalus durissus terrificus. J. Exp. Biol. 209, 2628-2636.

Cannon, W.B., 1929. Bodily Changes in Pain, Hunger, Fear and Rage. D. Appleton \& Co. New York (404 pp.).

Carravieri, A., Müller, M.S., Yoda, K., Hayama, S., Yamamoto, M., 2016. Dominant parasympathetic modulation of heart rate and heart rate variability in a wild-caught seabird. Physiol. Biochem. Zool. 89, 263-276.

Coote, J.H., Hilton, S.M., Perez-Gonzalez, J.F., 1979. Inhibition of the baroreceptor reflex on stimulation in the brain stem defence centre. J. Physiol. 288, 549-560.

De Groat, W.C., 1970. The actions of $\gamma$-aminobutyric acid and related amino acids on mammalian autonomic ganglia. J. Pharmacol. Exp. Ther. 172, 384-396.

De Vera, L., González, J., 1997. Power spectral analysis of short-term RR interval and arterial blood pressure oscillations in lizard (Gallotia galloti): effects of parasympathetic blockade. Comp. Biochem. Physiol. 118A, 671-678.

Decavel, C., Van den Pol, A.N., 1990. GABA: a dominant neurotransmitter in the hypothalamus. J. Comp. Neurol. 302, 1019-1037.

DiMicco, J.A., Abshire, V.M., 1987. Evidence for a GABAergic inhibition of a hypothalamic sympatho-excitatory mechanism in anesthetized rats. Brain Res. 402, 1-10.

DiMicco, J.A., Abshire, V.M., Hankins, K.D., Sample, R.H.B., Wible Jr., J.H., 1986. Microinjection of GABA antagonists into posterior hypothalamus elevates heart rate in anesthetized rats. Neuropharmacology 25, 1063-1066.

DiScala, G., Schmitt, P., Karli, P., 1984. Flight induced by infusion of bicuculline methiodide into periventricular structures. Brain Res. 309, 199-208.

Djojosugito, A.M., Folkow, B., Kylstra, P.H., Lisander, B., Tuttle, R.S., 1970. Differentiated interaction between the hypothalamic defence reaction and baroreceptor reflexes. I. Effects on heart rate and regional flow resistance. Acta Physiol. Scand. 78, 376-385.

Enok, S., Simonsen, L.S., Pedersen, S.V., Wang, T., Skovgaard, N., 2012. Humoral regulation of heart rate during digestion in pythons (Python molurus and Python regius). Am. J. Phys. 302, R1176-R1183.

Enok, S., Slay, C., Abe, A.S., Hicks, J.W., Wang, T., 2014. Intraspecific scaling of arterial blood pressure in the Burmese python. J. Exp. Biol. 217, 2232-2234.

Evans, M.S., Viola-McCabe, K.E., 1996. Midazolam inhibits long-term potentiation through modulation of GABA receptors. Neuropharmacology 35, 347-357.

Gähwiler, B.H., Brown, D.A., 1985. GABA B -receptor-activated $\mathrm{K}^{+}$current in voltageclamped $\mathrm{CA}_{3}$ pyramidal cells in hippocampal cultures. Proc. Natl. Acad. Sci. 82, 1558-1562.

Gebber, G.L., Snyder, D.W., 1970. Hypothalamic control of baroreceptor reflexes. Am. J. Phys. 218, 124-131.

Krnjević, K., 1974. Chemical nature of synaptic transmission in vertebrates. Physiol. Rev. 54, 418-540.

Kuwahara, M., Yayou, K., Ushii, K., Hashimoto, S., Tsubone, H., Sugano, S., 1994. Power spectral analysis of heart rate variability as a new method for assessing autonomic activity in the rat. J. Electrocardiol. 27, 333-337.

Kylstra, P.H., Lisander, B., 1970. Differentiated interaction between the hypothalamic defence area and baroreceptor reflexes. II. Effects on aortic blood flow as related to work load on the left ventricle. Acta Physiol. Scand. 78, 386-392.

Leite, C.A.C., Taylor, E.W., Guerra, C.D.R., Florindo, L.H., Rantin, F.T., 2009. The role of the vagus nerve in the generation of cardiorespiratory interactions in a neotropical fish, the pacu, Piaractus mesopotamicus. J. Comp. Physiol. 195A, 721-731.

Li, M., Hu, J., Chen, Z., Meng, J., Wang, H., Ma, X., Luo, X., 2006. Evidence for histamine 
as a neurotransmitter in the cardiac sympathetic nervous tone. Am. J. Phys. 291, $\mathrm{H} 45-\mathrm{H} 51$.

Lignot, J.H., Helmstetter, C., Secor, S.M., 2005. Postprandial morphological response of the intestinal epithelium of the Burmese python (Python molurus). Comp. Biochem. Physiol. 141A, 280-291.

Lillywhite, H.B., Albert, J.S., Sheehy III, C.M., Seymour, R.S., 2012. Gravity and the evolution of cardiopulmonary morphology in snakes. Comp. Biochem. Physiol. 161A, 230-242.

Lopes, O.U., Palmer, J.F., 1978. Mechanism of hypothalamic control of cardiac component of sinus nerve reflex. Q. J. Exp. Physiol. 63, 231-254.

Montano, N., Ruscone, T.G., Porta, A., Lombardi, F., Pagani, M., Malliani, A., 1994. Power spectrum analysis of heart rate variability to assess the changes in sympathovagal balance during graded orthostatic tilt. Circulation 90, 1826-1831.

Mosley, C.A.E., 2005. Anesthesia and analgesia in reptiles. Semin. Avian. Exotic Pet Med. 14, 243-262.

Natalini, C.C., 2007. Teoria e técnicas em anestesiologia veterinária. Artmed, Porto Alegre (296 pp.).

Nilsson, S., 2011. Comparative anatomy of the autonomic nervous system. Auton. Neurosci. 165, 3-9.

Olsen, R.W., Venter, J.C., 1986. Benzodiazepines/GABA Receptors and Chloride Channels: Structural and Functional Properties (Receptor Biochemistry and Methodology, Volume 5). Allan R. Liss, New York, pp. 351.

Ong, J., Kerr, D.I.B., 1990. GABA-receptors in peripheral tissues. Life Sci. 46, 1489-1501.

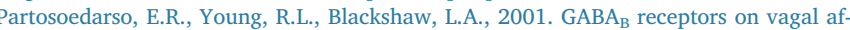
ferent pathways: peripheral and central inhibition. Am. J. Phys. 280, G658-G668.

Rataj, A.V., Lindtner-Knific, R., Vlahović, K., Mavri, U., Dovč, A., 2011. Parasites in pet reptiles. Acta Vet. Scand. 53, 1-20.

Reves, J.G., Fragen, R.J., Vinik, R., Greenblatt, D.J., 1985. Midazolam: pharmacology and uses. Anesthesiology 62, 310-324.

Rigel, D.F., 1988. Effects of neuropeptides on heart rate in dogs: comparison of VIP, PHI, NPY, CGRP, and NT. Am. J. Phys. 255, H311-H317.

Rosenbluth, A., Simeone, F.A., 1934. The interrelations of vagal and accelerator effects on the cardiac rate. Am. J. Phys. 110, 42-45.

Schreihofer, A.M., Guyenet, P.G., 2002. The baroreflex and beyond: control of sympathetic vasomotor tone by GABAergic neurons in the ventrolateral medulla. Clin. Exp. Pharmacol. Physiol. 29, 514-521.

Secor, S.M., 2008. Digestive physiology of the Burmese python: broad regulation of integrated performance. J. Exp. Biol. 211, 3767-3774.

Secor, S.M., Diamond, J., 1997. Effects of meal size on postprandial responses in juvenile Burmese pythons (Python molurus). Am. J. Phys. 272, R902-R912.

Secor, S.M., White, S.E., 2010. Prioritizing blood flow: cardiovascular performance in response to the competing demands of locomotion and digestion for the Burmese python, Python molurus. J. Exp. Biol. 213, 78-88.

Secor, S.M., Hicks, J.W., Bennett, A.F., 2000. Ventilatory and cardiovascular responses of a python (Python molurus) to exercise and digestion. J. Exp. Biol. 203, 2447-2454.

Semyanov, A., Walker, M.C., Kullmann, D.M., Silver, R.A., 2004. Tonically active GABA receptors: modulations gain and maintaining the tone. Trends Neurosci. 27, 262-269.

Skovgaard, N., Moller, K., Gesser, H., Wang, T., 2009. Histamine induces postprandial tachycardia through a direct effect on cardiac $\mathrm{H}_{2}$-receptors in pythons. Am. J. Phys. 296, R774-R785.

Snow, R.W., Krysko, K.L., Enge, K.M., Oberhofer, L., Warren-Bradley, A., Wilkins, L., 2007. Introduced populations of Boa constrictor (Boidae) and Python molurus bivittatus (Pythonidae) in southern Florida. In: Henderson, R.W., Powell, R. (Eds.), Biology of the Boas and Pythons. Eagle Mountain Publishing, Eagle Mountain, pp. 416-438.

Taylor, E.W., Jordan, D., Coote, J.H., 1999. Central control of the cardiovascular and respiratory systems and their interactions in vertebrates. Physiol. Rev. 79, 855-916.

Taylor, E.W., Leite, C.A.C., Sartori, M.R., Wang, T., Abe, A.S., Crossley II, D.A., 2014. The phylogeny and ontogeny of autonomic control of the heart and cardiorespiratory interactions in vertebrates. J. Exp. Biol. 217, 690-703.

Teixeira, M.T., Armelin, V.A., Abe, A.S., Rantin, F.T., Florindo, L.H., 2015. Autonomic control of post-air-breathing tachycardia in Clarias gariepinus (Teleostei: Clariidae). J. Comp. Physiol. 185B, 669-676.

Wang, T., Taylor, E.W., Andrade, D., Abe, A.S., 2001. Autonomic control of heart rate during forced activity and digestion in the snake Boa constrictor. J. Exp. Biol. 204, 3553-3560.

Wang, T., Altimiras, J., Axelsson, M., 2002. Intracardiac flow separation in an in situ perfused heart from Burmese python, Python molurus. J. Exp. Biol. 205, 2715-2723.

Wang, T., Altimiras, J., Klein, W., Axelsson, M., 2003. Ventricular haemodynamics in Python molurus: separation of pulmonary and systemic pressures. J. Exp. Biol. 206, 4241-4245.

Wilson, D., Heinsohn, R., 2007. Geographic range, population structure and conservation status of the green python (Morelia viridis), a popular snake in the captive pet trade. Aust. J. Zool. 55, 147-154.

Zaar, M., Overgaard, J., Gesser, H., Wang, T., 2007. Contractile properties of the functionally divided python heart: two sides of the same matter. Comp. Biochem. Physiol. 146A, 163-173.

Zaccone, G., Marino, F., Zaccone, D., 2011. Intracardiac neurons and neurotransmitters in fish. In: Farrell, A.P. (Ed.), Encyclopedia of Fish Physiology: From Genome to Environment. Academic Press, San Diego, pp. 1067-1072.

Zena, L.A., Gargaglioni, L.H., Bícego, K.C., 2013. Temperature effects on baroreflex control of heart rate in the toad, Rhinella schneideri. Comp. Biochem. Physiol. 179A, 81-88. 